\title{
Mulheres podem praticar lutas? Um estudo sobre as representações sociais de lutadoras universitárias ${ }^{1}$
}

Marco Antonio de Carvalho Ferretti Jorge Dorfman Knijnik

\begin{abstract}
Resumo: Historicamente, a mulher foi perseguida dentro do esporte, sofrendo de maledicências, proibições e de preconceitos. Isto piora quando se envolvem com modalidades que apresentam características "masculinas". Este estudo teve como objetivo pesquisar as representações de mulheres que praticam luta. Foram entrevistadas sete lutadoras universitárias, que se envolveram com atividade física na infância, na escola e incentivadas por pais; esta prática se encerrou na adolescência, para ser retomada novamente na adultez. As lutadoras apontam para a existência de preconceito sobre elas, e para a total ausência da mídia nas lutas femininas. Percebeu-se que muitas não se consideram lutadoras, e concluiu-se que isto é uma forma destas lidarem com o preconceito.
\end{abstract}

Palavras-chave: Mulheres. Esporte de combate. Luta.

\section{GÊNEROS E ESPORTES}

É difícil encontrar algum setor da atividade humana que não tenha sido genereficado, isto é, no qual não tenham ocorrido processos culturais designando simbolicamente, em termos dicotômicos e muitas vezes antagônicos, aquilo que seria mais adequado para que o homem, ou então para que a mulher, realizasse.

"Genereficar", isto é, colocar as coisas da vida na ordem dos gêneros, apondo normas, atitudes, símbolos e ações pertinentes aos

${ }^{1}$ Este trabalho é fruto da monografia de conclusão de curso de Bacharel em Esporte na Universidade de São Paulo do primeiro autor, orientado pelo segundo. O título faz referência e uma singela homenagem a outro texto, de autoria de Silvana Goellner (2000), que questiona se as mulheres poderiam jogar futebol.

* Bacharel em Esporte pela Universidade de São Paulo. E-mail: macferretti81@yahoo.com.br ** Licenciado e Mestre em Educação Física. Doutor em Psicologia. Docente da Escola de Educação Física e Esporte da Universidade de São Paulo e do curso de Educação Física da Universidade Presbiteriana Mackenzie. E-mail: jk@usp.br

Novimento, Porto Alegre, v.13, n. 01, p.57-80, janeiro/abril de 2007. 
sexos, é hierarquizar os valores numa ordenação que geralmente é bipolar e excludente. Entretanto, isto parece ser um processo corriqueiro e transcultural nas sociedades humanas. Ou seja, o gênero seria a construção cultural permanente daquilo que é considerado "de homem" ou "de mulher". Para Souza e Altmann (1999, p.53), "[...] gênero é aquilo entendido como a construção social que uma dada cultura estabelece ou elege em relação a homens e mulheres".

E isto que chamamos de algo tão comum nas coletividades humanas é um dado normalmente construído sobre as diferenças corporais perceptíveis. Nas sociedades contemporâneas, nas quais o esporte se transformou num fenômeno midiático com um valor absoluto e quase onipresente em nossas vidas, ele é um dos palcos nos quais se desenrola uma grande parte das definições sobre o que é ser homem ou ser mulher - isto é, o esporte é uma das instituições sociais em que, inclusive por sua corporeidade, se manifestam as ideologias sobre o masculino e o feminino que estão em permanente tensão. Conforme Salinas (2003), os valores femininos ensinados às mulheres no processo de socialização geralmente são antagônicos e vão de encontro aos códigos corporais transmitidos pelo esporte; em virtude da apreensão destes valores ser tão arraigada no processo de socialização, eles formam um habitus (no sentido bourdiano), ou seja, se impregnam na pessoa com tal força que até parecem determinados geneticamente, favorecendo desta forma o emprego das diferenças biológicas para justificar como natural a construção social dos gêneros.

Desta forma, o objetivo geral deste texto é discutir as representações sociais da mulher que pratica atividades de luta corporal, representações estas que ensejam uma análise de significados e aspectos simbólicos relativos às configurações de gênero em constante mutação na nossa época, sobretudo por serem as lutas uma atividade que continua sendo apontada, no imaginário social sobre os gêneros, como "coisa de homem". Para tal, apresentaremos aqui um estudo feito com lutadoras universitárias, tentando dissecar o que estas atletas pensam sobre si e sua atividade corporal.

Movimento, Porto Alegre, v.13, n. 01, p.57-80, janeiro/abril de 2007. 


\section{MULHER E ESPORTE: APONTAMENTOS HISTÓRICOS}

Para Goellner (2004), o esporte, este fenômeno social de visibilidade fabulosa, não é um fenômeno "a-histórico", que existe e paira sobre os intensos movimentos que cada sociedade produz. Ao contrário, a autora revela que este fenômeno é absolutamente contextualizado, expressando, mas também construindo os valores de cada época e espaço social - "em outras palavras, o esporte possui história" (GOELLNER, 2004, p.361).

Desta forma, a cada tempo e em cada local onde sua prática ocorre, o esporte foi e ainda é uma forma de expressão dos conflitos e possibilidades existentes em uma sociedade. Na Antiguidade Grega, por exemplo, a possibilidade de vida das mulheres era muito restrita, sendo reservado a elas o papel de procriar e cuidar dos filhos. Neste contexto, o esporte era uma prática geralmente proibida para elas. Desde os Jogos Olímpicos da Antiguidade, somente as jovens e solteiras tinham a permissão de assistir as competições com a finalidade explícita de escolher um marido e informar seus irmãos ou o pai sobre a escolha (MIRAGAYA, 2002).

Os Jogos Olímpicos da modernidade foram recriados por inspiração do nobre francês Barão de Coubertin em 1896. O Barão, homem de seu tempo e seguindo a tradição dos Jogos Olímpicos da Antiguidade, proibiu a participação das mulheres na competição moderna (KNIJNIK, 2003; MIRAGAYA, 2002).

Nas primeiras décadas do século XX, as mulheres conseguiram pouca presença no cenário esportivo e olímpico. Com o passar dos anos, já na metade do século passado, houve um incentivo ao esporte praticado por mulheres na União Soviética e no bloco do leste europeu, os quais não discriminavam suas mulheres atletas, e os países ocidentais voltaram suas atenções para o desempenho de suas mulheres (MIRAGAYA, 2002). Os Estados envolvidos na Guerra Fria incentivaram o esporte feminino para utilizar a contagem de medalhas nos jogos olímpicos como propaganda de seu sistema de governo.

Movimento, Porto Alegre, v.13, n. 01, p.57-80, janeiro/abril de 2007. 
60 Antigor Origimais Marco Antônio de Carvalho Ferretti e Jorge Dorfman Knijinik

Para Devide (2002), a Guerra Fria (1945-1991) foi uma alavanca para o esporte como um todo, mas especialmente para o esporte feminino, pois os EUA e a extinta URSS notaram que “[...] voltar o olhar para o desenvolvimento e o incentivo do esporte feminino, poderia ser uma forma de fazer sobressair um país no cenário mundial" (DEVIDE, 2002, p.716).

Em nosso país, entretanto, se algumas competições para mulheres eram realizadas, como os Jogos da Primavera, poderosas ideologias eram mobilizadas para cercear ou mesmo impedir as mulheres de praticarem esportes. A área médica no Brasil, ao final dos anos 1970, ainda estava presa a conceitos que negavam com veemência a participação feminina nos esportes. O famoso fisiologista Mário Carvalho Pini (1978) alegava que a mulher poderia até participar dos esportes, mas não deveria fazê-lo em diversas modalidades (como rúgbi, futebol, lutas, entre outras), porque os treinamentos ocasionariam um grande desgaste físico, além das conseqüências traumáticas e/ou estéticas dos contatos violentos propiciados por diversas destas modalidades.

Estas ideologias se transformaram em leis, como a promulgada no período do Estado Novo (1937 a 1945) e que vigorou no Brasil entre 1941 e 1975: o Decreto-lei n 3.199, cujo artigo 54 expressava que "[...] às mulheres não se permitirá a prática de desportos incompatíveis com as condições de sua natureza" (MOURÃO, 2002, p.833). Assim, além das barreiras ideológicas e culturais, a participação da mulher no esporte encontrava obstáculos legais. O governo militar proibiu a participação da mulher em certos esportes (como lutas, halterofilismo, futebol) através da Deliberação 7 (MOURÃO, 2002).

Se nos dias atuais essas leis caíram, e a presença da mulher no contexto esportivo aumenta a cada dia, no entanto, diversas questões e preconceitos ainda pesam sobre as mulheres atletas, especialmente quando pensamos, de um lado, na educação distinta que meninos e meninas recebem em relação às atividades esportivas; e, de outro lado, quando olhamos para o tratamento diferenciado que a mídia oferece às atletas já consagradas.

Mavimento, Porto Alegre, v.13, n. 01, p.57-80, janeiro/abril de 2007. 


\section{3 “EDUCANDO" AS MULHERES}

As instituições familiares e educacionais estabelecem “[...] valores e atitudes entre meninos e meninas possibilitando à criança, apenas, desempenhar um papel masculino ou feminino" (MELLO, $2002)^{2}$; ou seja, para o autor, impede-se um desenvolvimento corporal amplo, pois os meninos terão uma coordenação apenas "masculina" e as meninas somente aquela considerada "feminina".

Os pais e professores educam a criança de acordo com o seu sexo. Caso a criança faça algo que não corresponda ao seu sexo, ela será advertida pelo adulto, assim, "[...] a criança é influenciada a 'desejar' os tipos de brincadeiras, brinquedos e esportes que queira participar, não lhe sendo permitido a escolha do que ela realmente quer brincar" (MELLO, 2002).

Adelman (2003) encontrou esse "modelamento" das crianças por parte dos pais em entrevistas com amazonas. Algumas relataram que os pais não as deixavam fazer aula de hipismo por ser muito perigoso para meninas; os pais chegavam a pedir para que o treinador "pegasse duro" com seus filhos, mas não exigisse muito das filhas, pois, para eles, o treino deveria visar um futuro competitivo, enquanto que, para elas, seria somente um hobby.

Conforme Alonso (2002), as pessoas ao redor da criança fornecem prêmios para ela desde cedo, caso seja um garoto competitivo ou uma menina submissa.

Porém, há mulheres que conseguem superar essas barreiras. Mennesson (2000), em pesquisas com lutadoras, identificou que na infância e adolescência elas tinham comportamentos diferentes em relação a outras meninas; elas gostavam de competição, eram "bagunceiras", se vestiam de forma semelhante aos garotos e preferiam a companhia deles, além de possuírem uma coordenação incomum para garotas.

Descobrir fatores que fizeram uma menina escolher a vida esportiva seria importante para direcionar a política esportiva de

${ }^{2}$ Disponivel em: <http://www.castelobranco.br/prppg/revista/Textos/artigo/sexista.htm>

Movimento, Porto Alegre, v.13, n. 01, p.57-80, janeiro/abril de 2007. 
modo a obter um maior número de atletas competindo. Giuliano, Popp e Knight (2000) utilizaram um questionário em 84 universitárias atletas (40) e não atletas (44). As pesquisadoras fizeram a correlação entre a infância e os outros dados, comparando atletas e não atletas; as atletas geralmente tinham maior contato com brinquedos e jogos "masculinos", praticavam atividades físicas em grupos mistos ou predominantemente masculinos; elas se consideravam "meninas levadas" durante a infância. Foi identificado pelas pesquisadoras que as atletas, na infância, brincaram com brinquedos e jogos "masculinos", receberam maior incentivo para praticar esporte do que as meninas que se divertiam com brinquedos e brincadeiras femininas. As atletas que jogavam preferencialmente em grupos masculinos e que se classificaram como "meninas levadas" se sentiam com maior confiança nas suas habilidades do que as que jogavam mais com meninas. Comparando atletas de esportes tradicionalmente masculinos com as atletas de esportes tradicionalmente femininos, observou-se que as primeiras participaram mais de brincadeiras masculinas, e também mais de jogos cole-tivos, receberam mais incentivo de amigos e amigas e se classificavam mais como "meninas bagunceiras" do que as segundas.

\section{MÍDIA: O PARADOXO DO REFORÇO E DA RUPTURA DOS ESTEREÓTIPOS NO ESPORTE}

A mídia, segundo Freitas (2000), geralmente não relaciona a mulher à força ou à energia. Pode-se observar isso em propagandas esportivas, que normalmente utilizam mais homens. Quando jogos femininos são retratados na mídia, o são de forma erotizada, no sentido de atrair o público masculino heterossexual. Freitas (2000) observou isso nos jogos de vôlei feminino, onde a câmera dá mais importância ao "bumbum" da jogadora do que a sua jogada. Recentemente, nos Jogos Olímpicos de Atenas (2004), as atletas de voleibol de praia exigiram que a televisão não mostrasse tomadas que as constrangiam, de tal modo que estas eram fechadas em determinadas zonas erógenas de seus corpos; ao contrário, queriam que as transmissões tivessem focos mais abertos, transmitindo o jogo em si.

Mavimento, Porto Alegre, v.13, n. 01, p.57-80, janeiro/abril de 2007. 
Mesnner, Duncan e Cooky (2003) acreditam que as filiais da ESPN que transmitem "luta livre" feminina destinam seus programas para homens heterossexuais que não consideram esporte feminino como algo que mereça respeito, e o entretenimento esportivo é tratado como voyeurismo, banalizando a mulher atleta; na luta livre pornô (wrestling porno), as "atletas" são sexualizadas e ironizadas (um entrevistador chegou a perguntar à lutadora Sable se ela podia contar até 10).

Entretanto, nem sempre uma luta de mulheres torna-se atraente apenas pelo apelo erótico. Um jornalista especializado em lutas se colocou esta questão ao indagar sobre a noite em que ocorreu a luta de "Iron" Mike Tyson x Seldon, em que uma das lutas preliminares era de boxe feminino (Chisty Martin x Melinda Robinson): "O que foi mais legal? Assistir um apavorado Seldon se jogar na lona depois de um golpe relar em seu cabelo ou a Chisty nocautear Melinda em quatro assaltos?" (OHATA, 2005, p.D3). Nesta coluna sobre lutas, percebe-se que o jornalista já avança, mostrando que o importante ("legal", segundo ele) seria ver lutas de qualidade, a qual seria atestada pela duração maior da luta entre as mulheres no caso reportado. Esta afirmação em um jornal do porte da Folha de São Paulo - somada a algumas reportagens que tem enfocado lutadoras brasileiras de diversas modalidades (como tae-kwon-do, por exemplo) - deixa entrever que algumas mudanças em representações sobre mulheres que lutam começam a ocorrer.

Em filmes de grande repercussão, mulheres que lutam têm sido retratadas de formas as mais diversas: no filme "Mulher gato" (Cat-Woman), é notável a sensualidade da protagonista, aliada a sua força sobre-humana:

[...] ver Halle Berry, que é uma bela mulher, naquela roupa de couro nada a ver, com chicote, fazendo poses de garotas de programa, infelizmente, já deu para sentir que estava vindo coisa ruim por aí $[\ldots]$ além de um desnecessário e ridículo rebolado, só pra dar o tom sexy à personagem (CUNHA, 2004). ${ }^{3}$

${ }_{3}^{3}$ Disponivel em <http://www.cineplayers.com/ critica.php?id=282.>

Movimento, Porto Alegre, v.13, n. 01, p.57-80, janeiro/abril de 2007. 
64 Antigor Origimais Marco Antônio de Carvalho Ferretti e Jorge Dorfman Knijinik

Já sobre o laureado filme "Menina de Ouro", que conta a história de uma mulher que entra no mundo do boxe, a crítica escreveu que:

[...] Não há nenhum momento em que Swank [atriz do filme] é mostrada como sexy ou uma caricatura cômica, mas alguém determinada, baseada em sua paixão e ética de trabalho. O modo como a personagem cresce, tanto física quanto emocionalmente, salta aos olhos, num tipo de papel convencionalmente masculino (KRIVOCHEIN, 2005). ${ }^{4}$

Aqui cabe também mencionar, a título de exemplificação de mudanças nas representações sobre lutadoras, como as meninas já vêm sendo mostradas nos desenhos infantis, abrindo-se a possibilidade da criação de novos imaginários sobre meninas e mulheres lutadoras: sejam garotas poderosas (como o caso do famoso desenho das "Meninas Super Poderosas"), no qual as protagonistas Lindinha, Docinho e Florzinha lutam e encaram seus opositores; ou mesmo filmes de animação com meninas disfarçadas de homens (no caso do desenho animado "Mulan", da Disney, cuja heroína é uma adolescente chinesa que se disfarça de homem para se alistar no exército e lutar contra hordas de bárbaros invasores, no lugar de seu pai); o fato é que está ocorrendo uma intensa reinterpretação simbólica sobre mulheres que vão à luta, literalmente e de fato.

\section{OS GÊNEROS “EM LUTA” NAS LUTAS}

A divisão genereficada é patente no esporte. Existem práticas esportivas "masculinas" e "femininas", sendo que as lutas, apesar das modificações em curso apontadas anteriormente, ainda são identificadas como esportes masculinos, pois, para Souza e Altmann (1999), os esportes competitivos, violentos, com contato físico, são vistos como uma forma de tornar um menino em homem, aumentando a sua virilidade, masculinidade, capacidade de desprezar a

${ }^{4}$ Disponível em <http://www.zetafilmes.com.br/criticas/meninadeouro.asp?pag=meninadeouro> Mavimento, Porto Alegre, v.13, n. 01, p.57-80, janeiro/abril de 2007. 
dor, controle do corpo e vontade de ganhar - ou seja, são esportes cujos rituais balizam questões próprias de uma masculinidade ideal a ser atingida e conquistada (RIAL, 2000; SILVA, 1999).

Conforme Mourão (2002), as mulheres que praticam os esportes classificados para os homens são rotuladas de masculinas, e, para praticarem esses esportes, sofrem com o preconceito tanto de homens quanto de mulheres.

Por causa destes estereótipos, mesmo querendo transpor essa barreira, ou seja, sair das atividades características reservadas apenas ao seu sexo, as pessoas teriam receio de fazê-lo por medo de ridicularizações do grupo social, ou mesmo com receio de serem excluídas ao serem rotuladas como homossexuais, carregando toda a carga de preconceito e discriminação que sofrem as pessoas com opções sexuais distintas da norma heterossexual hegemônica. Ou seja, existe um grande policiamento das normas de gênero no interior do esporte, e aquele, ou aquela, que se desviar um pouco poderá ser intensamente criticado por este patrulhamento rígido relacionado ao gênero no interior do mundo esportivo.

Nas lutas, as mulheres, além de correrem o "risco" de serem rotuladas de lésbicas, chegaram a ser impedidas de praticar. Wacquant (2002) observou no início da década de 1980 uma academia de boxe localizada em Woodlawn, comunidade afroamericana de baixa renda na cidade de Chicago, na qual não havia boxeadoras. Era permitida a presença de namoradas e esposas dos boxeadores somente em dias anteriores a uma grande luta ou após uma grande vitória, e lhes era facultado ficarem sentadas em um banquinho.

Para Rial (2000), a mera entrada da mulher no esporte não alterará as estruturas excludentes e chauvinistas deste, mas sim poderá dar início a uma mudança nos valores que dificultam a sua entrada; para Souza e Altmann (1999, p.58), as mudanças de valores já vêm ocorrendo, pois, atualmente, “[...] aos homens é dado o direito de praticar o voleibol, sem riscos para a sua masculinidade, e o futebol passa a ser praticado por mulheres".

Movimento, Porto Alegre, v.13, n. 01, p.57-80, janeiro/abril de 2007. 
66 Astigor Origimais Marco Antônio de Carvalho Ferretti e Jorge Dorfman Knijinik

\section{METODOLOGIA}

No intuito de atingir o objetivo geral deste trabalho, isto é, apreender as representações sociais de mulheres que praticam luta sobre a sua atividade, passamos a relatar o estudo de campo que viabilizou a consecução deste objetivo.

Antes deste relato, todavia, é importante considerar, mesmo que brevemente, o que alguns autores mencionam sobre o que são estas representações sociais que aqui se almejam atingir.

A teoria das representações sociais é proveniente da abordagem clássica de Durkheim, no campo da investigação sociológica. Em escritos datados de 1898, Durkheim (1970) afirma que as idéias e representações comuns e compartilhadas por determinadas coletividades não são internas às consciências dos componentes destas comunidades, pois não são provenientes diretamente dos indivíduos enquanto seres isolados. Ao contrário, são frutos da cooperação das consciências, e que o resultado final, a idéia - matriz resultante das consciências -, apesar de contar com a parte que cada indivíduo apôs, é a combinação de todos estes, não sua mera justaposição.

Em linhas gerais, o pressuposto básico da teoria das representações sociais é que o pensamento é um fato social - assim, o pensamento dos membros de uma comunidade consiste na decorrência daquilo que é possível pensar em determinados contextos históricos e sociais (MOSCOVICI, 1985).

Desta forma, no sentido de apreender estas representações que um grupo de lutadoras forma e constrói a respeito de sua própria prática, realizamos aqui entrevistas estruturadas com sete universitárias, entre 20 e 36 anos, que praticam lutas, sendo três boxeadoras, duas capoeiristas e duas caratecas, e apenas uma destas participa regularmente de competições.

As perguntas versavam sobre a sua infância esportiva, sobre o papel da mídia no esporte feminino; havia perguntas também sobre questões de gênero e mesmo sobre os estados psicológicos das praticantes de luta. $\mathrm{O}$ intuito era traçar um painel sobre a Movimento, Porto Alegre, v.13, n. 01, p.57-80, janeiro/abril de 2007. 
vivência esportiva especifica com lutas destas mulheres. Ressaltamos que todas elas foram informadas exaustivamente sobre os procedimentos e finalidades da pesquisa, e que, concordando com estes, assinaram de livre e espontânea vontade o consentimento esclarecido em participar da pesquisa, o qual garantia o anonimato de suas informações.

Após as transcrições das entrevistas, submetemos o material à análise a partir da metodologia criada e sugerida por Lefèvre e Lefèvre (2004), intitulada de método do Discurso do Sujeito Coletivo (DSC) - indicado exatamente, segundo seus autores, para a tabulação de pesquisas com entrevistas estruturadas; por meio desta metodologia, inicialmente se anotam as expressões-chaves de cada uma das entrevistas; posteriormente, se destacam as idéias centrais destas expressões-chave, idéias estas que sintetizam o teor daquele discurso; de posse destas idéias-centrais, agrupamos as mesmas de acordo com as suas semelhanças, formando assim categorias, a partir das quais os discursos foram efetivados. Os resultados formam uma série de discursos-síntese - que são os discursos do sujeito coletivo - e que representam discursos indi-viduais semelhantes agrupados, ou seja, as próprias representações sociais daquele grupo ou subgrupo sobre os temas discutidos, mantendo a idéia de grupos de pessoas diante de um tema. A seguir, apresentam-se fragmentos destes discursos coletivos e uma série de inferências e comentários ao redor das idéias.

\section{COMBATE FALADO: O QUE DIZEM, ENFIM, ESTAS LUTADORAS}

Todas as entrevistadas se envolveram com o esporte na escola: "Na infância era só na escola, educação física e às vezes com os vizinhos, jogávamos vôlei, mas pouco, era mais na escola mesmo, onde eu tinha as aulas de educação física" (DSC1).

Pereira (1984), em sua dissertação de mestrado, pioneira no estudo das mulheres brasileiras no esporte, já apontava a importância da escola para o envolvimento das garotas com o esporte. Das atletas estudadas naquela época, $46,7 \%$ começaram a praticar esporte na escola, sendo que $20 \%$ começaram a praticar pela influência da família.

Movimento, Porto Alegre, v.13, n. 01, p.57-80, janeiro/abril de 2007. 
68 Astigor Origimais Marco Antônio de Carvalho Ferretti e Jorge Dorfman Knijinik

Algumas atletas falam que na infância eram muito ativas e tinham estímulo dos pais: "Os meus pais sempre estimularam, na verdade meu irmão fez caratê e meus pais perguntaram se eu queria fazer também" (DSC2).

Cox e Thompson (2000) encontraram o mesmo comportamento nas jogadoras de futebol da Nova Zelândia, que relataram ter recebido incentivo masculino para praticarem esportes, por meio dos pais, irmãos, amigos e professores, e que na infância se sentiam diferentes de outras meninas por serem mais ativas.

Entretanto, as lutadoras aqui relatam que ocorreu uma diminuição da atividade física na adolescência: “[...] sempre foram brincadeiras ativas, mais com meninos, [...] mas atualmente fiquei parada. Fui assim até uns 12 anos, depois na adolescência eu parei" (DSC3). Esta fala mostra que algumas meninas, a partir da adolescência, começam a se comportar de forma mais tradicionalmente feminina. Esta diminuição da atividade com a chegada da adolescência também é descrita na literatura internacional. As boxeadoras entrevistadas por Mennesson (2000) - cuja maioria relatou que havia se identificado com os modelos masculinos durante a infância - revelaram que, ao chegarem à adolescência e na idade adulta, re-adaptaram seus comportamentos para se adequarem aos padrões hegemônicos da feminilidade. Assim, mesmo estando em um esporte que valoriza as "características masculinas", elas se esforçam por parecerem femininas, mas uma feminilidade diferente, que não é frágil ou passiva.

Outra fala mostra a dificuldade de conciliar a casa com o esporte: "Os meus pais ficaram às vezes com os meus filhos para eu poder praticar esporte, isso ajuda bastante, às vezes você não tem com quem deixar os seus filhos e não pode praticar esporte" (DSC4).

Mourão (2002) confirma este problema dizendo que, devido aos papéis de gênero, a mulher fica impedida de realizar viagens atléticas, ou mesmo dedicar-se em treinamentos de longa temporada. Tudo o que afasta a mulher do mundo da casa é algo que merece uma batalha, pois as configurações de gênero ainda colocam como prioridade para a mulher os cuidados com a família e a casa. E as Movimento, Porto Alegre, v.13, n. 01, p.57-80, janeiro/abril de 2007. 
mulheres-atletas procuram dar conta disso, elas estão "[...] dispostas a assumir diferentes cargos no mercado de trabalho, e no esporte ainda procuram associar sua função aos cuidados com os filhos e com a casa" (MOURÃO, 2002, p.843).

Adelman (2003) obteve respostas semelhantes ao entrevistar mulheres que se dedicam ao hipismo, as amazonas. Elas relataram que pararam de praticar esporte porque não era possível conciliar família, filhos e trabalho com as competições e treinos. Em geral, os maridos não as apoiavam - contrariamente ao que ocorria com os cavaleiros, cujas esposas normalmente estavam presentes na torcida das provas. Uma amazona relatou que nas competições o único marido na arquibancada era o dela. As jogadoras de voleibol que Adelman (2003) usou como contraponto em seu estudo, também reconheceram a dificuldade em ser atleta e querer construir uma vida familiar. Uma das jogadoras revelou que o homem pode casar, ter filhos e continuar jogando, enquanto que, se a mulher desejar fazer a mesma coisa, terá dificuldades.

Recentemente, Lajolo (2005) noticiou um fato que mostra como lentamente estas representações de papéis tradicionais estão se adequando e se modificando: Paula Pequeno, jogadora da seleção brasileira de voleibol, que havia acabado de ter a sua primeira filha, deixou a criança de quatro meses com o pai (também atleta do selecionado nacional de handebol) para poder disputar o mundial de sua modalidade no Japão, ocorrido em novembro de 2006. Ou seja, já existem exemplos de atletas que combinam o alto nível de sua profissão, disputando competições por seleções nacionais, com a maternidade, sem abrir mão de nenhuma, e contando com o auxílio de homens dedicados.

Em relação à mídia, a visão das lutadoras já mostra que, em meio às habituais constatações de falta de cobertura e atenção por parte da imprensa, existem aquelas que vislumbram mudanças na relação desta com o esporte. Há algumas que reclamam que a mídia ignora as lutadoras, mas também outras que percebem certas melhoras e avanços, mesmo que envoltos em preconceitos antigos. Existem mesmo atletas que pensam que a mídia poderia influenciar a mulher a praticar modalidades de lutas.

Movimento, Porto Alegre, v.13, n. 01, p.57-80, janeiro/abril de 2007. 
70 Astigor Origimais Marco Antônio de Carvalho Ferretti e Jorge Dorfman Knijinik

A primeira fala coletiva sobre o assunto coloca que "[...] eu nem vejo na mídia essas coisa, a mulher lutando é muito pouco visto, não sei nem se é criticado ou não, sei que é muito pouco" (DSC5). Esta percepção já foi comprovada em diversos estudos. Recentemente, Mesnner, Duncan e Cooky (2003), ao analisarem três filiais da ESPN Sport Center - a KNBC, KABC e KCBS -, encontraram respectivamente que, em seus noticiários e reportagens, apenas $10,6 \%, 8,6 \%$ e 5,8\% foram notícias de esporte com mulheres; as matérias neutras ou com ambos os sexos foram de $3,1 \%, 4,1 \%$ e $2,4 \%$, respectivamente, sendo que o restante do material foi composto por notícias sobre atletas homens.

Contudo, como afirmado anteriormente, há aquelas que vislumbram mudanças: "Hoje em dia acho que melhorou bastante, recentemente vi uma carateca, que eles estavam mostrando como ela era bonitona, mas ainda tem um pouco desse mito do tipo que é mulhermacho" (DSC6). Ou seja, esta fala coletiva já vê uma melhoria no tratamento da mídia com relação às atletas, mas ainda percebe o preconceito, que está sendo suavizado com o tempo. Esta lenta mudança da mentalidade foi percebida por Riemer e Visio (2003) ao compararem os resultados obtidos em 1965 com a Classificação de Metheny - em que as pessoas classificam qual o esporte é mais "masculino" ou mais "feminino" - com os da atualidade. Os pesquisadores encontraram que o beisebol e futebol tornaram-se menos "masculinos" e o softbol menos "feminino". A mudança de mentalidades que isto traduz ainda ocorre de forma gradual, e dessa forma ainda permanecem resíduos, como percebem e falam as lutadoras aqui estudadas. Algumas acreditam piamente que a mídia, colocando em exposição mulheres que lutam, pode influenciar outras mulheres a praticarem estas modalidades: "[...] acho que a partir do filme Matrix, onde apareciam as mulheres lutando kungfu, virou uma moda" (DSC7). Miragaya (2002) acena também com esta hipótese, de que a maior presença da mulher esportista nos meios de comunicação faz com que meninas e mulheres tenham novos modelos de heroína a serem seguidos.

Algumas falas das lutadoras fizeram com que se abrisse uma nova perspectiva de análise. Elas comentaram como vieram a se Movimento, Porto Alegre, v.13, n. 01, p.57-80, janeiro/abril de 2007. 
interessar por uma modalidade de luta, pois estas fazem parte do ambiente "masculino" e isso poderia ser um motivo para afastá-las. $\mathrm{Na}$ verdade, apesar da luta ser considerada masculina, elas realizaram uma operação social e psicológica de "feminização" da atividade, para poderem praticá-la sem "culpas".

Um dos discursos apurados mostra que elas não consideram a capoeira uma modalidade muito masculina - " [...] tem muitas mulheres que praticam capoeira, não é um esporte tão masculino, e não é só exercício, tem cultura" (DSC8).

Mennesson (2000) também encontrou universitárias que praticavam savate (boxe francês) e que preferiam utilizar mais os chutes a socos, pois, para a autora, os chutes supostamente remeteriam à dança, que é considerada "mais feminina", tal como na capoeira utilizam-se principalmente as pernas para atacar, e há movimentos ritmados e dançados.

Há um discurso que claramente indica que o interesse em fazer lutas, mais do que competir e combater, está mais ligado à questão da atividade física em si, de estar em forma e bem com o próprio corpo:

[...] o professor mandava treinar mesmo, como se fosse mais para ir treinar profissional e isso meio que não era o meu interesse, mas as minhas amigas me incentivavam a fazer do meu jeito (DSC9).

Aqui, se apresenta claramente um conflito de interesses, o técnico, que quer a luta com o seu espírito tradicional, e o discurso destas informantes, que transformaram a luta em algo "de seu interesse".

Para Mennesson (2000), as mulheres que começam boxe após os 20 anos preferem a forma suave do esporte, que é uma versão mais fácil, ou como o nome diz, é uma versão "suavizada" (soft) do esporte, enquanto que as que começam cedo preferem a versão "mais dura" (hard). A forma que se pratica boxe na universidade aqui estudada é a suavizada, utilizam-se luvas maiores do boxe amador e o mais importante é acertar o golpe no adversário e não derrubá-lo, diferentemente do boxe profissional.

Movimento, Porto Alegre, v.13, n. 01, p.57-80, janeiro/abril de 2007. 


\section{Astigor Originais Marco Antônio de Carvalho Ferretti e Jorge Dorfman Knijinik}

O boxe praticado na universidade não visa o profissionalismo, a maioria das alunas não percebe diretamente um preconceito contra mulheres lutadoras, ou contra elas mesmas. Entretanto, elas declaram que têm algumas ressalvas quanto à prática do boxe profissional por mulheres, pois treinando profissionalmente a mulher vai sair da forma física "feminina" para obter melhores performances, o que é questionado pelas lutadoras universitárias.

\section{[...] em nível profissional, a mulher quer treinar tudo bem, mas eu acho que é um pouco forte, um pouco rude, para ir fazer profissional mesmo, ir apanhar, não sei, tem dias que acho que não dá para fazer profissionalmente (DSC10).}

Outro discurso reforça esta questão da estética, pois a atleta comenta que, como não se encaixou na atividade desejada (musculação), partiu para o boxe porque trabalha o corpo como um todo, mas reforça que as pernas também são trabalhadas: "[...] tem que se movimentar no ringue e você movimenta as pernas, apesar de que a atenção maior é do tronco para cima, [...], mas movimenta as pernas também" (DSC11). Deste modo, retoma-se a ligação com as pernas, uma parte do corpo que simbolicamente é muito vinculada ao feminino e que, mesmo musculosa, não significa uma aparência tão masculinizada como se trabalhasse preferencialmente os músculos da cintura para cima.

Outra análise que as atletas fizeram foi quando questionadas se o esporte "tem sexo", ou seja, o que as atletas pensavam do fato de existirem esportes classificados como "masculinos" ou como "femininos".

"Não tem sexo, mas homem é diferente da mulher". Esta idéia predominou nas falas das lutadoras, expondo que as mulheres fazem esporte de um jeito diferente, são mais fracas, e, logo, lutam de modo distinto daquele dos homens:

Hoje na turma tinha 4 homens e eu de mulher só [...] não dá para você querer fazer uma competição entre sexos, logicamente os homens têm mais força

[...] acho que na parte de aprendizado, as mulheres têm um lado mental mais protetor então fica difícil

Mavimento, Porto Alegre, v.13, n. 01, p.57-80, janeiro/abril de 2007. 
para elas atacarem, mas se bem que têm mulheres que vão lá e botam a cara e a coragem (DSC12).

A força "natural" do homem prevalece e nenhuma delas parece perceber que, se treinadas, podem ficar tão ou até mais fortes que homens. Entretanto, elas entendem que existem algumas que "vão com a cara e a coragem". Menesson (2000) relata que as que começaram mais cedo, ainda crianças ou no início da adolescência, lutam de modo hard e encaram o adversário sem temores. É provável que as lutadoras entrevistadas aqui, por terem começado mais tarde, sintam a dificuldade do aprendizado, e isto é automaticamente traduzido como uma diferença biológica, entre os sexos, e não compreendido como algo culturalmente construído nos diversos processos de socialização pelos quais passaram.

"Não tem sexo, mas homem é diferente da mulher", também levanta a idéia de que, dentro da luta, não são pessoas sexuadas, mas fora dela a conversa é outra: as atletas comentam que "[...] é como um teatro, você dentro do ringue é uma coisa, você está ali para fazer o seu esporte, fora dele é outra coisa, você tem a tua vida" (DSC13). Ou seja, elas parecem bradar contra qualquer tipo de comentário sexuado sobre as atletas nas lutas, e procuram proteger a sua feminilidade fora dos ringues, mostrando que lutar não tem relação com opção ou preferências sexuais. No entanto, esta é a mistura que sempre se procura realizar, colar a identidade de gênero de uma atleta que optou por uma modalidade mais "masculina", com a sua identidade sexual. Wright e Clarke (1999) mostraram o quanto as notícias sobre o esporte feminino defendiam e queriam garantir a feminilidade das jogadoras, construindo o que os autores denominaram de uma heterossexualidade compulsória na qual as atletas eram "blindadas" de qualquer comentário sobre sua aparência mais masculina, e se mostravam apenas os aspectos aparentemente heterossexuais destas.

As atletas também falaram sobre como o seu entorno, os seus grupos sociais e familiares as enxergam. Novamente aqui aparecem aquelas que percebem mudanças, e outras que ainda se vêem em meio a preconceitos, mesmo que velados ou ocultos.

Movimento, Porto Alegre, v.13, n. 01, p.57-80, janeiro/abril de 2007. 
74 Astigor Origimais Marco Antônio de Carvalho Ferretti e Jorge Dorfman Knijinik

"O professor sempre que vai pedir ou mostrar o exemplo pega uma pessoa com o nível acima para mostrar o movimento, ele só pega homem" (DSC14). Para Mello (2002), os homens, na sua história de vida, têm maiores possibilidades de trabalhar a coordenação, e assim tem um repertório motor maior, enquanto que as meninas são poupadas de algumas atividades físicas por serem do "sexo frágil". Assim, o homem vai executar o golpe com maior precisão, apesar de não se justificar, e as atletas se queixam disso, que até nas demonstrações de golpes mais simples sejam eleitos os mais habilidosos.

As atletas também percebem as dificuldades das mulheres em se aproximarem de uma atividade de lutas: “[...] acho que das pessoas que estão lá dentro não tem problema nenhum, mas tem muito mais homem do que mulher" (DSC15). Esta maior procura pela atividade por parte dos homens claramente ocorre porque desde sempre os meninos são mais estimulados ao combate, à luta. Segundo Alonso (2002), os meninos são mesmo "premiados" por sua agressividade, sejam estes prêmios concretos ou sob formas de elogios, afetividade, recompensas emocionais, aceitação. Por outro lado, segundo a autora, as meninas são reprimidas nos seus impulsos agressivos e são estimuladas, também sob forma de premiações ou sanções sociais, a terem comportamentos opostos, submissos e passivos. De acordo com Mello (2002), a sociedade sexista transmite às crianças que meninas e meninos são opostos e nota-se esse comportamento quanto aos brinquedos, brincadeiras e esportes: para os meninos, brinquedos de lutas e ação; para elas, brinquedos com apetrechos domésticos, enfeites, de manipulação mais passiva.

Além da visão dos terceiros, as atletas também mostraram a própria visão sobre si mesmas, se colocando como lutadoras, como se vêem tanto física quanto psicologicamente. Uma delas comentou que "não sou lutadora" - não se enxergam como lutadoras, sendo no máximo "treinadora": "[...] na verdade eu falo que sou mais treinadora, treino mais a modalidade do que luto" (DSC16). Esse posicionamento é uma forma de proteção contra os preconceitos que uma lutadora pode ser vítima. Adelman (2003), ao entrevistar uma jogadora de vôlei, relata que após o treino ou jogo ela vai se

Mavimento, Porto Alegre, v.13, n. 01, p.57-80, janeiro/abril de 2007. 
maquiar, colocar brinco e saia, e outra atleta relatou que procura aflorar mais a feminilidade fora da quadra. A autora interpretou esta condição e estas atitudes como um jeito das atletas buscarem meios de se protegerem do preconceito que ainda grassa contra as atletas.

Por fim, ao serem questionadas sobre a prevalência dos homens nos esportes com luta, as mulheres acabaram novamente esbarrando em questões de gênero. Muitas delas possuem um discurso que já fala da mudança que ocorreu nas mentalidades, e que o ingresso da mulher está quebrando o preconceito:

\section{[...] acho que ainda tem a visão de quem luta e é mais agressivo é do homem, que a mulher é mais delicada e não participa [...] e agora a mulher co- meçou a entrar e as pessoas estão vendo que elas podem competir igual ao homem faz (DSC17).}

Conforme Alonso (2002), a mulher que se destaca no esporte ganha respeito e reconhecimento social, quebrando o estereótipo feminino de fraqueza, mas ganhado um olhar erótico dos homens sobre o corpo modelado.

\section{FINALIZANDO..}

"Finalizar" é o termo empregado no meio das lutas para encerrar uma disputa. É quando um adversário consegue bater o outro, derrubá-lo, fazendo com que este desista, peça "água”. É um ippon no judô.

As lutadoras aqui estudadas não têm a pretensão de "finalizar" ninguém, são universitárias que lutam, porém de forma suave. Descobriram que as lutas podem ser uma forma agradável de manter o corpo em forma, uma opção diferente de atividade física, mas que ainda não é muito bem vista para mulheres, então, criam formas, ideologias e produzem discursos que podem deixar a atividade mais feminina, mais palatável a sua identidade de gênero. Elas lutam, porém sem "pegar forte", afinal, muita força é atributo natural dos homens, segundo elas.

Movimento, Porto Alegre, v.13, n. 01, p.57-80, janeiro/abril de 2007 
76 Astigor Origimais Marco Antônio de Carvalho Ferretti e Jorge Dorfman Knijinik

Sendo assim, elas possuem um discurso que, se de um lado as protege contra qualquer inferência sobre a sua sexualidade ou mesmo sua identidade de gênero, ao dizerem que o esporte não tem sexo, ao mesmo tempo, denunciam preconceitos, pois questionam o quanto a mídia não apóia mulheres que lutam, ou mesmo o quanto os professores estão mais ligados aos homens, pois estes são mais habilidosos, são os que demonstram os golpes nas aulas e que angariam mais atenção dos professores.

Outros modos que as atletas possuem para que a sua atividade seja aceita por elas mesmas e pelos outros, sem questionamentos quanto à sua feminilidade, é a contrariedade e mesmo a negação da luta enquanto atividade profissional para a mulher. Elas devem lutar para buscar a saúde, agora lutar "para valer", de forma profissional, talvez seja coisa de homem, é algo rude para a mulher. Assim, elas não se consideram como verdadeiras lutadoras, são mais mulheres que treinam lutas, "treinadoras", como se denominaram. A própria capoeira, como uma luta mais dançada, entra no rol das atividades que não são tão masculinas, e assim "liberadas" para as mulheres.

Não deixa de ser interessante o quanto as questões de gênero aqui se colocam, e como estas ideologias se mostram em constante construção, mais ainda no meio da atividade esportiva e corporal, ambiente ideal para que estes símbolos se recriem e se transfigurem a todo momento. Segundo Connell (1995), apesar da complexidade e mesmo das contradições que o termo possui e evoca, "[...] o gênero é, nos mais amplos termos, a forma pela qual as capacidades reprodutivas e as diferenças sexuais dos corpos humanos são trazidos para a prática social e tornadas parte do processo histórico" (CONNELL, 1995, p.189). Assim, um meio no qual os corpos são usados, transformados e suados, é "perfeito" para que as diferentes concepções de gênero aflorem e mesmo se debatam entre si.

Neste estudo, mesmo que restrito a poucas atletas, mostrouse que as lutas estão ajudando neste processo de reconfiguração das representações sociais de gênero no meio universitário no Brasil. As lutas, ao entrarem na universidade, e ao atingirem camadas de mulheres que de algum modo gostaram de esportes desde a sua infância - mas se viram forçadas a interromperem esta atividade Movimento, Porto Alegre, v.13, n. 01, p.57-80, janeiro/abril de 2007. 
em algum momento da adolescência, em função de normas de gênero estritas e estreitas, que impunham modelos corporais ligados a uma concepção hegemônica de feminilidade - enfim, essas lutas de algum modo estão provocando reflexões e criando novos símbolos que certamente influenciarão, num futuro breve, novas opções para que as meninas e mulheres possam se desenvolver corporalmente.

Este talvez seja um grande passo para livrar tanto as meninas das amarras de gênero que as cercam, impedindo-as de serem livres e viverem plenamente os seus corpos, quanto os meninos, que muitas vezes impelidos a terem comportamentos extremamente agressivos, não conseguem vivenciar atividades corporais e de lutas como um momento de auto-superação e autoconhecimento.

Este processo de reflexão e construção tem um grande impulso quando os pesquisadores passam a questionar as praticantes, pois ao pararem para pensar, elas acabam por verbalizar questões que certamente irão trazer novos significados à sua prática, e conseqüentemente estimular a atividade de toda uma gama de pessoas que estão ao seu lado, ampliando possibilidades para que as lutas, e as atividades corporais possam ser vivenciadas por todos, sem barreiras ou preconceitos de espécie alguma.

Can women practice fighting? A study on the social representations of the College female fighters

Abstract: Historically in Sports, Women have been chased after by defamations, prohibitions and prejudices of all sorts. This even gets worse when they get involved with some kinds of fight modalities considered "masculine". This study aims at researching female fighters' representations. Seven college fighters were interviewed. They started this physical activity in their early childhood at school or encouraged by their parents, quit it during adolescence and have retaken it as a grownup. They point out that prejudice against them is strong and complain about the total indifference of Media when it comes to female fightings. It was noticed that most of them don't consider themselves as fighters which is a way of dealing with the prejudice against them. Keywords: Women. Combat sport. Fights.

Movimento, Porto Alegre, v.13, n. 01, p.57-80, janeiro/abril de 2007. 
78 Astigos Originais Marco Antônio de Carvalho Ferretti e Jorge Dorfman Knijinik

\begin{tabular}{l}
\hline ¿Mujeres pueden practicar luchas? Uno estudio \\
sobre las representaciones sociales de \\
luchadoras universitarias. \\
Resumen: Históricamente la mujer fue perseguida \\
dentro del ámbito deportivo, sofriendo de difamaciones, \\
prohibiciones y de preconceptos. Esto se ha puesto \\
peor a partir del momento que estas se han envol- \\
vido con modalidades deportivas que tienen carac- \\
terísticas "masculinas". Este estudio tubo el objeti- \\
vo de pesquisar las representaciones de mujeres \\
que practican luchas. Se han entrevistado 7 \\
luchadoras universitarias que han practicado el \\
actividad física durante la infancia, en las escuelas \\
y incentivadas por sus padres; la práctica se enceró \\
en la adolescencia y fue retomada novamente en \\
la edad adulta. Las combatientes enseñan la \\
existencia de preconceptos sobre ellas y la total falta \\
de media en las luchas femeninas. Se ha constatado \\
que muchas de ellas no se consideran combatientes, \\
así pues se ha concluido que esto es una manera de \\
protección contra el preconcepto. \\
Palabras clave: Mujeres. Deporte de combate. Lucha.
\end{tabular}

\section{REFERÊNCIAS}

ADELMAN, M. Mulheres atletas: re-significações da corporalidade feminina. Estudos Feministas, Florianópolis, v. 11, n. 2, p.445-465, 2003.

ALONSO, L. K. Máquina, palco, igreja: corpo feminino e esportes. In: FÓRUM DE DEBATES SOBRE MULHER \& ESPORTE MITOS E VERDADES, 2. 2002. Anais... São Paulo: Escola de Educação Física e Esporte da Universidade de São Paulo, 2002. p.S64-66.

CONNELL, R. Políticas da masculinidade. Educação e Realidade, Porto Alegre, v. 20, n. 2 , p.185-206, 1995

COX, B.; THOMPSON, S. Multiple Bodies: Sportswomen, Soccer and Sexuality. International Review for the Sociology of Sport, London, v. 35, n. 1, p.5-20, 2000 .

CUNHA, R. Mulher-Gato. Cine-players, 2004. Disponível em: <http:// www.cineplayers.com/ critica.php?id=282>. Acesso em: 19 jul. 2005.

DEVIDE, F. P. História das mulheres nos Jogos Olímpicos Modernos. Coletânea de textos em estudos olímpicos. Rio de Janeiro: Gama Filho, 2002. v. 1, p.705736.

DURKHEIM, E. Sociologia e filosofia. Rio de Janeiro: Forense Universitária, 1970.

Movimento, Porto Alegre, v.13, n. 01, p.57-80, janeiro/abril de 2007. 
FREITAS, S. G. Mulher, Esporte, Sexo, Imagem Corporal e Hipocrisia. In: FÓRUM DE DEBATE SOBRE MULHER \& ESPORTE MITOS E VERDADES, 1. 2000. Anais... São Paulo: Universidade de São Paulo, 2000, p.10-14.

GIULIANO, T. A.; POPP, K. E.; KNIGHT, J. L. Footballs versus barbies: childhood play activities as predictors of sport particopation by women. Sex Roles, Heidelberg, v. 42 , n. $3 / 4$, p.159-181, 2000

GOELLNER, S. V. Pode a mulher praticar futebol? In: CARRANO, P. C. R. Futebol: paixão e política. Rio de Janeiro: DP\& A, 2000. p.79-93.

GOELLNER, S. V. Mulher e esporte no Brasil: fragmento de uma história genereficada. In: SIMÕES, A. C. ; KNIJNIK, J. D. O mundo psicossocial da mulher no esporte: comportamento, gênero, desempenho. São Paulo: Aleph, 2004, p.35973.

KNIJNIK, J. D. A mulher brasileira e o esporte: seu corpo, sua história. São Paulo: Mackenzie, 2003.

KRIVOCHEIN, B. Menina de Ouro de Clint Eastwood. Zeta Filmes. Disponível em <http://www.zetafilmes.com.br/criticas/meninadeouro.asp?pag=meninadeouro>. Acesso em: 19 jul. 2005.

LAJOLO, M. Mulheres abrem espaço, mas não calçam as luvas. Folha de São Paulo, São Paulo, 28 out. 2005. Folha Esporte, v. 85, n. 27967, p.D10.

LEFÈVRE, F.; LEFÈVRE, A. M. C. O Pensamento coletivo como soma qualitativa 2004. Disponível em:<http://hygeia.fsp.usp.br/quali-saude/soma\%20qualitativa\% 209\%20de\%20fevereiro\%20de\%202004.htm>. Acesso em: 22 ago. 2004.

MELLO, L. M. Meninos e meninas como reféns de uma sociedade sexista. Revista Motricidade, Santa Maria da Feira-Portugal, n. 2, 2002. Disponível em: <http:/ /www.castelobranco.br/prppg/revista/Textos/artigo/sexista.htm>. Acesso em: 29 de nov, de 2005

MENNESSON, C. 'Hard' woman and 'soft' woman. International Review For The Sociology of Sport, Londres, v. 35, n. 1, p.21-33, 2000.

MESNNER, M. A.; DUNCAN, M. C.; COOKY, C. Silence, Sports Bras, and Wrestling Porn: Women in Televised Sports News and Highlights Shows. Journal of Sport \& Social Issues, Londres, v. 27, n. 1, p.38-51, 2003

MIRAGAYA, A. A mulher olímpica: tradição versus inovação. In: TURINO, M.; DACOSTA, L. (org). Coletânea de textos em estudos olímpicos. Rio de Janeiro: Gama Filho 2002. v. 1, p.763-792.

MOSCOVICI, S. On social representation. In: FORGAS, J. P. (org). Social cognition. London: Academic, 1985.

Movimento, Porto Alegre, v.13, n. 01, p.57-80, janeiro/abril de 2007. 
80 Astigor Origimais Marco Antônio de Carvalho Ferretti e Jorge Dorfman Knijinik

MOURÃO, L. Vozes femininas e o Esporte Olímpico no Brasil. In: TURINO, M.; DACOSTA, L. (org.). Coletânea de textos em estudos olímpicos. Rio de Janeiro: Gama Filho, 2002. v. 1, p.831-849.

OHATA, E. Mulher de Ouro. Folha de São Paulo, São Paulo, 11 fev. 2005. Folha Esporte, p.D3.

PEREIRA, L. E. Mulher e Esporte: um estudo sobre a influência dos Agentes de Socialização em Atletas Universitárias. 1984. Dissertação (Mestrado). São Paulo: Escola de Educação Física e Esporte da Universidade de São Paulo, 1984.

PINI, Mario Carvalho. A mulher no esporte: fisiologia esportiva. Rio de Janeiro: Guanabara Koogan, 1978. p.204-220.

RIAL, C. S. Rúgbi e judô: esporte e masculinidade. In: PEDRO, J. M.; GROSSI, M. $P$. (org). Masculino Feminino Plural: gênero na interdisciplinaridade. Florianópolis: Mulheres, 2000. p.241-254.

RIEMER, B. A.; VISIO, M. E. Gender Typing of Sports: An Investigation of Metheny's Classification. Quarterly for Exercise and Sport, Reston, v. 74, n. 2, p.193-204, 2003.

SALINAS, Carmen. Generando otras potencias: fútbol y género: Caso Club Boca Juniors. Lecturas: EF y Deportes, Buenos Aires, v. 8, n. 56, 2003. Disponível em: <http://www.efdeportes.com/efd56/genero.htm>. Acesso em: 10 de out. 2004.

SILVA, S. G. O conflito identitário: sexo e gênero na constituição das identidades. Revista Brasileira de Sexualidade Humana, São Paulo, v. 10, n. 1, p.70-85, 1999.

SOUZA, E. S.; ALTMANN, H. Meninos e meninas: Expectativas corporais e implicações na educação física escolar. Cadernos CEDES, Campinas, v. 19, n. 48, p.52-68, 1999.

WACQUANT, L. Corpo e alma: notas etnográficas de um aprendiz de boxe. Rio de Janeiro: Relume Dumará, 2002.

WRIGHT, J.; CLARKE, G. Sport, the Media and the Construction of Compulsory Heterosexuality: A Case Study of Women's Rugby Union. International Review for the Sociology of Sport, Londres, v. 34, n. 3, p.227-243, 1999.

Recebido em: 01/12/2005

Aprovado em: 08/08/2006

Mavimento, Porto Alegre, v.13, n. 01, p.57-80, janeiro/abril de 2007. 